\title{
Orofaciodigital syndrome type III in two sibs
}

\author{
R A Smith, D Gardner-Medwin
}

\begin{abstract}
A brother and sister with mental retardation, malformations of the cerebellar vermis, characteristic 'metronome' eye movements, lingual hamartomas, and postaxial polydactyly are described. The clinical overlap with the OFD group of syndromes, in particular OFD III and OFD VI, and Joubert's syndrome is discussed. If OFD III syndrome is to be recognised as a distinct entity, these two cases represent the second and third cases reported.
\end{abstract}

( $\mathcal{H}$ Med Genet 1993;30:870-2)

The orofaciodigital (OFD) syndromes are a group of syndromes with considerable heterogeneity that have been subdivided on the basis of distinguishing clinical and genetic features. We present the second report of OFD type III in two affected sibs. The principal features were lingual hamartomas, postaxial polydactyly, malformations of the cerebellar vermis, and characteristic 'metronome' eye movements. One sib had the Dandy-Walker syndrome.

\section{Case reports}

CASE 1

Case 1, a girl, presented to the neurology department at the age of 16 days. Both parents were healthy; the mother was 36 and the father 37 years old. The pregnancy was normal with iron supplementation the only drug taken. Labour was induced at 37 weeks' gestation for maternal hypertension and prolonged rupture of the membranes. Delivery was by emergency caesarian section for failure to progress in the second stage of labour. The birth weight was $4220 \mathrm{~g}$ ( $>97$ th centile) and the occipitofrontal head circumference was $43.2 \mathrm{~cm}$ (well above the 97 th centile). Several abnormalities were noted. There was a prominent forehead with large anterior and posterior fontanelles (fig 1), postaxial polydactyly of both hands (fig 2), syndactyly of the fourth and fifth toes of both feet, and mild correctable talipes equinovarus deformities of both feet. Dimples were noted on the lateral aspects of both knees. There were two nodules on the anterior aspect of the tongue (fig 3). There was no visual fixation and unusual eye movements were noted. These consisted of slow, rhythmical, alternating, conjugate lateral eye movements, the eyes staying for about one second at the extreme of lateral gaze then swinging to the other side for one second with a frequency of 16 per minute (fig 1). These movements were continuous while she was awake, stopping only when she began to fall asleep. The pupils were small but reactive to light. The fundi were normal. Vertical doll's eye movements were normal and lateral

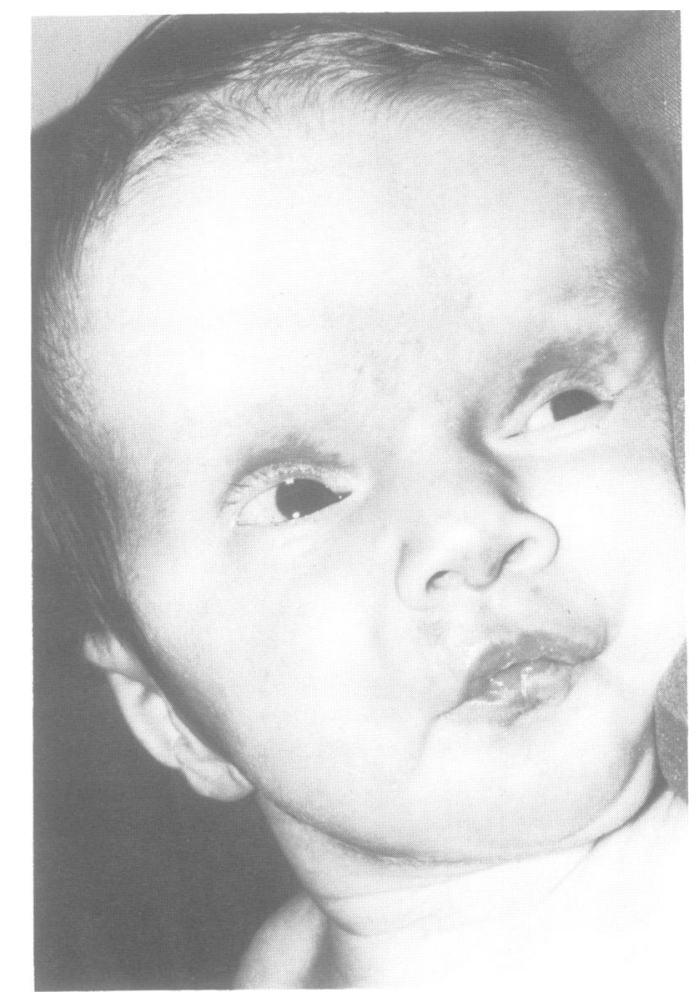

Figure 1 Case 1 showing prominent forehead and conjugate lateral deviation of eyes.

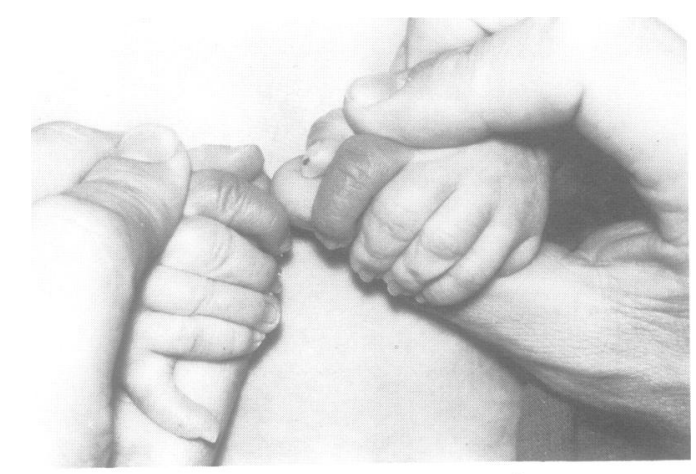

Figure 2 Case 1 showing bilateral postaxial polydactyly.

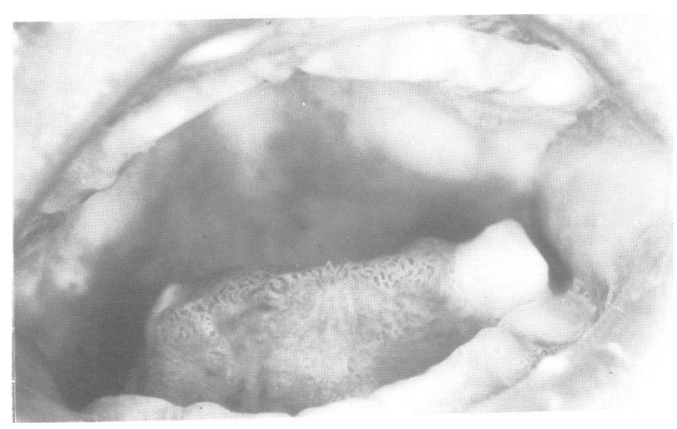

Figure 3 Case 1 showing tongue nodules. 4AQ.

Received 30 March 1993. Accepted 21 April 1993. Correspondence to
Dr Smith, 42 Moor
Crescent, Gosforth

Department of Newcastle General Road, Newcastle upo Tyne NE4 6BE, UK. D Gardner-Medwin

Correspondence to 
doll's eye movements were present but were overridden by the spontaneous movement.

CT scan of the head showed a large DandyWalker cyst with a moderate degree of hydrocephalus and striking midline cerebellar hypoplasia. The rate of growth of the head was closely monitored and by 2 months it had increased to $50.8 \mathrm{~cm}$. A cystoperitoneal shunt was inserted. Excision of the tongue nodules and extra digits was performed at 5 months and histology of the nodules showed evidence of minor salivary gland tissue but no neoplasia. She was slow to pass her early developmental milestones, sitting at 27 months and first walking at 3 years 9 months. At this age she only spoke a few words with meaning; her first sentences were at 5 years 4 months. Visual fixation developed at one or other extreme of lateral gaze, as she appeared to learn to retain the eyes there for increasing periods of time. Only at the age of 6 years did she begin to develop the ability to hold her eyes at or near the central point. Assessment of visual acuity showed no refractive error and assessment of hearing was normal. Although the oscillation persists, it is no longer rhythmic and there is now more voluntary control.

There were brothers aged 11 (case 2) and 6 years; the younger brother was unaffected. One other brother had died at the age of 10 weeks of sudden infant death syndrome. Both parents were normal with no relevant past medical history.

\section{CASE 2}

Case 2, the older brother, had several abnormal features in common with his sister. Five similar lumps on his tongue had been removed early in his life (histology showed hamartomata). He had a natal tooth which was removed and later had dental malocclusion. He had postaxial polydactyly on the left hand and a bifid fifth finger on the right. Other abnormalities noted were a unilateral single palmar crease, mild correctable talipes equinovarus present at birth, a high arched palate, a right inguinal hernia, and bilateral partial posterior choanal atresia. At the age of 11 years he also displayed a striking abnormality of his eye movements consisting of rotatory nystagmus and a tendency for the eyes to deviate to the right or left limits of lateral gaze (fig 4). The eyes tended to stay in the extreme of lateral gaze and he had difficulty in maintaining the eyes in the position of primary fixation. At the age of 17 years he was able to hold his gaze at the central point momentarily but still showed slow irregular horizontal eye movements. Generally when fixing his gaze he did so at either the right or left extreme of lateral gaze. Assessment of visual acuity indicated a mild hypermetropia as he got older. The appearance of the optic fundi, the electroretinogram, and visual evoked responses under anaesthesia were normal. Hearing was normal. He was moderately mentally retarded with severely subnormal spatial orientation and construction skills, but only just below average verbal comprehension skills. He did not have hydroceph-

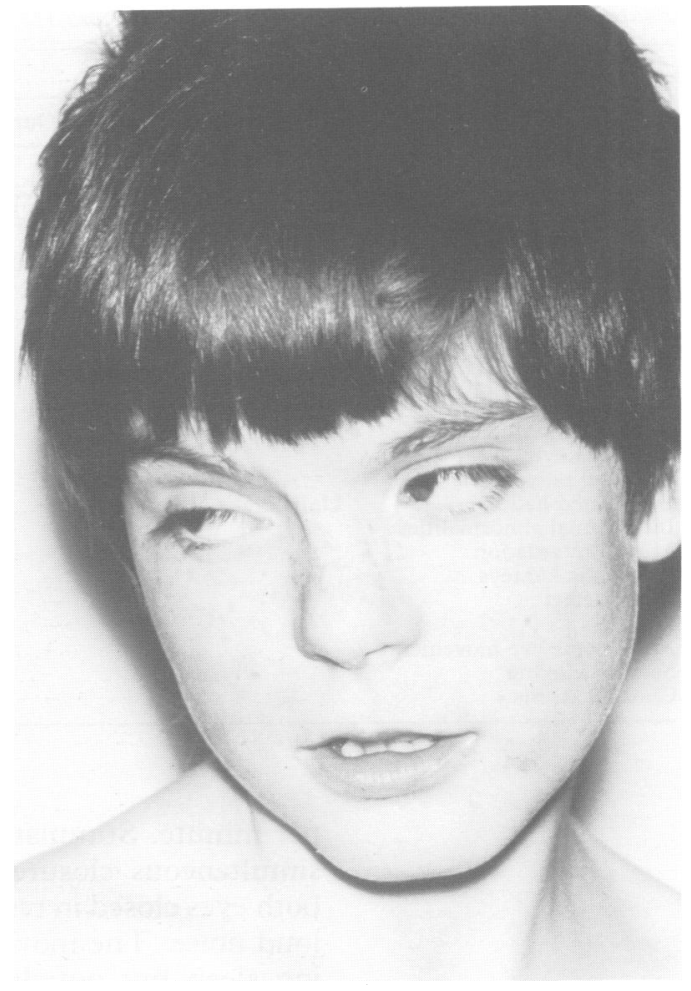

Figure 4 Case 2 showing conjugate lateral deviation of the eyes.

alus and his CT scan aged 12 years, although of rather poor quality, did give some indication of an abnormality of the cerebellar vermis. He had several generalised tonic clonic convulsions associated with fever when young. An EEG was normal. At 18 years he developed a mild scoliosis with a primary curve in the upper lumbar spine, convex to the left. There were no vertebral abnormalities.

\section{Discussion}

The OFD syndromes have recently been reviewed by Baraitser ${ }^{1}$ and Toriello. ${ }^{2}$ PapillonLeague and Psaume ${ }^{3}$ originally described what has now been labelled as OFD syndrome type I. OFD syndrome type II (Mohr's syndrome ${ }^{45}$ ) is much less common than type I and shares some of the features, the main differentiating feature being bilateral duplication of the hallux. Toriello $^{2}$ has tentatively further classified types III, IV, V, and VI variants of the OFD syndromes. Features of OFD syndrome types I, II, and III are shown in the table.

Type III refers to a single case report by Sugarman et $a l^{6}$ of a syndrome present in two sisters who had facial, lingual, and hand abnormalities, and profound mental retardation. The most significant and distinguishing finding was an abnormality of eye movement present in one of the sisters. Not only was this considered to be a feature of a new variant of OFD syndrome but also the eye movements themselves were considered unique as a congenital disorder of eye movement. The movements were described as ceaseless winking of the eyelids of five minutes duration alternating from one eye to the other as a continuous rhythmic seesaw movement with reciprocal movements occurring approximately 12 times 
Features of the orofaciodigital syndromes $I, I I$, and III.

\begin{tabular}{|c|c|c|c|c|c|c|}
\hline & \multirow[t]{3}{*}{ OFD I } & \multirow[t]{3}{*}{ OFD II } & \multicolumn{4}{|c|}{ OFD III } \\
\hline & & & \multicolumn{2}{|c|}{ Our cases } & \multicolumn{2}{|c|}{ Sugarman et $a l^{6}$} \\
\hline & & & 1 & 2 & 1 & 2 \\
\hline Inheritance & X linked D & AR & \multicolumn{2}{|c|}{ AR } & \multicolumn{2}{|c|}{ AR } \\
\hline Pseudocleft upper lip & + & + & - & - & - & - \\
\hline Lobulated tongue & + & + & + & + & + & + \\
\hline Tongue nodules & + & + & - & - & - & - \\
\hline Alveolar frenulae & + & + & - & - & - & - \\
\hline Cleft palate & + & + & - & - & + & - \\
\hline Aplasia of lateral incisors & + & - & - & - & $?$ & $?$ \\
\hline Aplasia of central incisors & - & + & - & - & $?$ & ? \\
\hline Supernumerary teeth & - & - & - & + & + & + \\
\hline Alopecia and milia & + & - & - & - & - & - \\
\hline Brachydactyly & + & + & - & - & + & + \\
\hline Postaxial polydactyly & + & + & + & + & + & + \\
\hline Duplicated hallux & Unilateral & Bilateral & - & - & - & - \\
\hline Intracranial abnormalities & + & + & + & $?$ & $?$ & $?$ \\
\hline Mental retardation & + & + & + & + & + & + \\
\hline Polycystic kidneys & + & + & - & - & - & - \\
\hline Heart defect & - & + & - & - & - & - \\
\hline Deafness & - & + & - & - & $?$ & $?$ \\
\hline Metronome eye movements & - & - & + & + & + & - \\
\hline Seesaw winking & - & - & - & - & + & - \\
\hline Choanal atresia & - & - & - & - & + & - \\
\hline
\end{tabular}

per minute. Stimulation of one eye led to the simultaneous closure of both eyes; similarly both eyes closed in response to a bright light or loud noise. The movements disappeared during sleep but not during conversation. Also present was an alternating horizontal conjugate deviation of the eyes each lasting one to two seconds. She was unable to fix or follow an object and visual acuity could not be determined. It is interesting to note that although the abnormalities of eye movement are similar in their cases and ours, with alternating lateral conjugate deviation of the eyes, the alternating seesaw winking of the eyelids was not present in the cases we describe. The possible anatomical and neurophysiological explanations for the abnormal eye and winking movements were discussed by Sugarman et al ${ }^{6}$ but there was no satisfactory explanation. The only abnormal investigation was an EEG abnormality with generalised 3 to $5 \mathrm{cps}$ high voltage slow waves. These ocular abnormalities along with frontal bossing, low set ears with large tragi, lobed, hamartomatous tongue, dental malocclusion and supernumerary teeth, bifid uvula, postaxial polysyndactyly of the hands and feet, short sternum, kyphosis, and profound mental retardation led to the designation of a new variant of the OFD syndromes.

Some of the dysmorphic features in the two cases we have described overlap with type I OFD. The presence of abnormal eye movements in both sibs, however, would be in favour of classifying them as OFD type III. Of interest is the presence of the Dandy-Walker anomaly in one of our cases. Haumont and Pelc $^{7}$ have reported the Dandy-Walker malformation in two female sibs with other phenotypic features compatible with type II OFD syndrome, although eye movements were not commented on. Reardon $e t a l^{\beta}$ reported a boy with features of OFD type II and a subarachnoid cyst above the fourth ventricle with hypoplasia of the superior cerebellar vermis and hydrocephalus. He did have abnormal 'jerky' eye movements without pendular nystagmus but this was probably secondary to abnormal visual function as visual evoked responses were abnormal. The two cases described by Sugarman et $a l^{6}$ were both mentally retarded but CNS imaging was not performed. It would seem that intracranial abnormalities occur in all three OFD syndromes and are not specific to any type. Varadi et $a l^{9}$ described six children from an inbred gypsy colony with reduplication of the big toes, supernumerary fingers, cleft lip/ palate, and lingual nodule associated with somatic and motor retardation. Absence of the cerebellar vermis, olfactory bulbs and tracts, and fossa interpeduncularis, cholangiodysplasia, and congenital heart disease were noted at necropsy of the proband. All cases died early with the oldest living to 6 years. This syndrome has been referred to as OFD $\mathrm{VI}^{2}$ and shows phenotypic overlap with the cases we describe. The only comment on eye movements was that there was no visual fixation or following.

Joubert's syndrome ${ }^{10}$ also shows some phenotypic overlap with cases we describe and with OFD III and VI. The features common to all are cerebellar vermis hypoplasia, hypotonia, developmental delay, abnormal eye movements, polydactyly, and lingual hamartoma (present in only four cases in the series of Joubert's syndrome described by Saraiver and Baraitser ${ }^{10}$ ). A range of oculomotor abnormalities have also been described including oscillatory movements, abnormalities of saccades, and nystagmus. The main distinguishing feature in Joubert's syndrome, however, is episodic hyperpnoea which was absent in our cases, as were chorioretinal coloboma, tongue protrusion, and occipital meningoencephalocele. The presence of retinal dystrophy and renal cysts was thought by Saraiva and Barais$\operatorname{ter}^{10}$ to define a separate group.

The cases we describe, therefore, are similar to OFD III as described by Sugarman et al, ${ }^{6}$ but show some phenotypic overlap with OFD VI, Joubert's syndrome, and the case described by Reardon et al. ${ }^{8}$ If a separate OFD syndrome (type III) is to be accepted then these two cases represent the second and third cases reported.

The presence of two affected sibs in this family, with normal parents, would be compatible with autosomal recessive inheritance.

1 Baraitser M. The orofaciodigital syndromes. 7 Med Genet 1986;23:116-19.

2 Toriello HV. Heterogeneity and variability in the orofacial-digital syndromes. Am f Med Genet 1988;4:149-59.

3 Papillon-League $M$, Psaume J. Une malformation hereditaire de la muqueuse buccale, brides et freins anormaux. Rev Stomatol 1954;55:209-22.

$4 \mathrm{Mohr}$ OL. A hereditary sublethal syndrome in man Avhandl Norske Videnkab Akad Mat Naturv Klasse 1941;14:3-18.

5 Rimoin DL, Egerton MT. Genetic and clinical heterogeneity of oral-facial-digital syndromes. $\mathcal{f}$ Pediatr 1967;91:683-4.

6 Sugarman GI, Katakia M, Menkes J. See-saw winking in familial oral-facio digital syndrome. Clin Genet $1971 ; 2: 248-54$.

7 Haumont D, Pelc S. The Mohr syndrome: are there two variants? Clin Genet 1983;24:41-6.

8 Reardon W, Harbord MG, Hall-Craggs MA, Kendall B, Brett EM, Baraitser M. Central nervous system malformations in Mohr's syndrome. F Med Genet 1989;26:659-63.

9 Varadi V, Szabo L, Papp Z. Syndrome of polydactyly, cleft lip/palate or lingual lump, and psychomotor retardation in endogamic gypsies. $\mathcal{F}$ Med Genet 1980;17:119-22.

10 Saraiva JM, Baraitser M. Joubert syndrome: a review. $A m \mathcal{F}$ Med Genet 1992;43:726-31. 